Jurnal Mahasiswa BK An-Nur : Berbeda, Bermakna, Mulia

Volume 4 Nomor 1 Tahun 2018

Tersedia Online: https://ojs.uniska-bjm.ac.id/index.php/AN-NUR

ISSN. 2460-9722

\title{
LAYANAN KONSELING KELOMPOK DENGAN TEKNIK BEHAVIORAL CONTRACT DALAM MENUMBUHKAN KARAKTER DISIPLN SISWA DI SMA PGRI 2 BANJARMASIN TAHUN AJARAN2017/2018
}

\author{
Puspha Fandini, Sultani, Didi Susanto \\ Universitas Islam Kalimantan Muhammad Arsyad Al-Banjari \\ puspa.1094@gmail.com
}

\begin{abstract}
ABSTRAK
Penelitian ini dilaksanakan berdasarkan dilapangan yang ada di kelas XI-IPS2 di SMA PGRI 2 Banjarmasin ada beberapa siswa yang tidak disiplin diakibatkan oleh rendahnya perilaku sisiwa. Melalui layanan konseling kelompok dengan teknik behavioral contract diharapkan disiplin siswa ini dapat ditingkatkan.

Hasil penelitian diperoleh persentase siswa tidak disiplin siswa di kelas XI-IPS2 sebelum mendapatkan layanan dikategori rendah dengan rincian sebagai berikut:AHSXI IPS2 kriteria rendah tidak disiplin, ANP XI-IPS2 kriteria rendah tidak disiplin, AT kriteria rendah tidak disiplin, MK kriteria sangat rendah tidak diisplin, MS kriteria rendah tidak disiplin, MT XI-IPS2 kriteria rendah tidak disiplin, dan RL kriteria rendah tidak disiplin. Persentase rata-rata tidak disiplin siswa di kelas XI-IPS2 selama pemberian tindakan setelah siklus I AHS XIIPS2 kategori sedang, ANP kriteria sedang, AT kriteria sedang, MK XI-IPS2 kriteria sedang MS kriteria rendah, MT kriteria sedang, RL kriteria sedang, Persentase setelah siklus 2 di kategori tinggi dengan AHS kriteria tinggi, ANP XI-IPS2 kriteria tinggi, AT kriteria tinggi MK kriteria tinggi, MS kriteria tinggi, MT kriteria tinggi, RL kriteria sangat tinggi.
\end{abstract}

Kata Kunci : Konseling Kelompok, Teknik Behavioral Contact Karker, Disiplin

\section{ABSTRACT}

This research was conducted based on the field in the class XI-IPS2 in SMA PGRI 2 Banjarmasin there are some students who are not discipline caused by low side behavior. Through group counseling service with behavioral contract technique expected this student discipline can be improved.

The results of the study showed that the percentage of non-disciplinary students in class XI-IPS2 before obtaining low-categorized services with the following details: AHSXI IPS2 undisciplined low criterion, ANP XIIPS2 low criterion undisciplined, AT low criterion not discipline, MK criteria very low diisplin, MS lowdisciplinary criteria, MT XI-IPS2 undeserved low criteria, and low RL undisciplined criteria. Average percentage of non-discipline of students in class XI-IPS2 during grace of action after cycle I AHS XI-IPS2 medium category, moderate ANP criterion, moderate AT criteria, MK XI-IPS2 medium criterion MS criterion low, medium criteria MT, moderate criterion RL, Percentage after cycle 2 in high category with high criterion AHS, high ANP XI-IPS2 criterion, high AT criterion criteria MK, MS criteria high, high criteria MT, RL criteria are very high.

Keywords: Group Counseling, Behavioral Contact Karker Technique, Discipline

Dipublikasikan Oleh:

UPT Publikasi dan Pengelolaan Jurnal

Universitas Islam Kalimantan Muhammad Asyad Al-Banjarmasin 


\section{PENDAHULUAN}

Pendidikan merupakan sistem dan cara meningkatkan kualitas hidup manusia dalam segala aspek kehidupan di dunia. Pendidikan mempunyai peranan penting dalam menentukan kemajuan sebuah Negara. Oleh karena itu, jika ingin memajukan sebuah Negara terlebih dahulu harus dimulai dengan meningkatkan kualitas pendidikan yang ada. Pendidikan harus menjadi prioritas utama pemerintah. Oleh karena itu, pemerintah melakukan reformasi dalam bidang pendidikan.

setiap manusia membutuhkan pedidikan sampai kapan dan dimana pun ia berada. Pendidikan sangat penting artinya tanpa pendidikan manusia sulit berkembang bahkan akan terbelakangg Jarkawi ( 2016). Mencapai hal tersebut peran guru-guru sangatlah penting terutama guru Bimbingan dan Konseling mengenai masalah-masalah atau hal-hal di luar pengajaran akan tetapi menunjang tercapainya tujuan pendidikan dan pengajaran disekolah. Bimbingan dan konseling di sekolah dibentuk untuk memenuhi perkembangan peserta didik dalam proses pengembangan emosi dan norma kehidupan yang ada di sekolah maupun masyarakat. Bimbingan dan konseling menangani masalah-masalah atau hal-hal di luar bidang pengajaran yang menghambat tercapainya tujuan pendidikan.

karakter akhir-akhir ini marak dibicarakan di media massa dan menjadi isu utama pendidikan nasional. Berbagai kalangan berbicara tentang pendidikan karakter, baik akademisi, pemerhati pendidikan, praktisi, maupun masyarakat umum. Topik ini menjadi sentral pembicaraan banyak orang disebabkan oleh kemerosotan moral bangsa termasuk pelajar. Dari pengertian pendidikan tersebut, pendidikan memiliki tujuan yang luhur. Keluhuran tujuan tersebut selayaknya tercermin dari potensi diri yang tergali, sikap dan tingkah laku yang bermoral dari peserta didik selaku subyek pendidikan. Untuk mencapai proses pendidikan perlu dikembangkan strategi pendidikan karakter yang terintegrasi dan pembelajaran secara terencana dan terprogram dengan baik hingga menghasilkan lulusan candekia, bekerakter, dan mampu tampil kometitif dalam pergaulan internasional sesuai yang diharapkan Susanto (2014).

Maka dari itu pentingnya pendidikan karakter untuk diterapkan dalam lembaga pendidikan. Kerena itu lembaga pendidikan formal sebagai wadah resmi Pembina generasi muda dihadap meningkatkan perannya dalam bentuk keperibadian peserta didik melalui peningkatan intensitas dan kualitas pendidik karakter. Pendidikan tentang disiplin sangat penting dalam perkembangan siswa, karena dapat menanamkan sikap bertanggung jawab, mandiri dan berperilaku positif dalam menjalankan kegiatan
ISSN. 2460-9722

sehari-hari di sekolah. Penerapan kedisiplinan di sekolah akan membuat siswa berperilaku dan bersikap patuh dan taat kepada peraturan sekolah, tidak ada lagi siswa yang terlambat, membolos, membuat kerusuhan, dan terlambat dalam melaksanakan tugas. Tujuan dari kedisiplinan siswa di sekolah untuk mengembangkan dan mengarahkan diri siswa agar terlatih dan terkontrol dalam bertingkah laku yang pantas (Titik Rumsari, dkk, 2009: 35). Hal tersebut dapat dijelaskan bahwa tujuan dari sekolah tidak hanya mencerdaskan siswa dalam bidang akademik saja, tetapi juga dalam mengembangkan diri siswa untuk bersikap dan berperilaku yang pantas sehingga siswa terarahkan pada penanaman dan pemahaman terhadap pola kehidupan yang disiplin.

Hari Santoso (2011) menjelaskan bahwa perilaku disiplin diharapkan dapat membentuk karakter siswa di sekolah yang ditunjukkan pada perilaku positif. Peraturan tata tertib sekolah dibuat untuk mendidik siswa agar disiplin dan dapat melaksanakan tugas-tugas di sekolah dengan penuh tanggung jawab. Penerapan sikap disiplin di sekolah akan bermanfaat bagi pengembangan karakter siswa. Adapun dari indikator disiplin tersebut yaitu membiasakan hadir tepat waktu, membiasakan mematuhi aturan, menggunakan pakaian sesuai jadwal.

Hal tersebut dapat diketahui dari siswa-siswa yang terlambat datang ke sekolah, tidak masuk sekolah tanpa keterangan, keluar pada saat pelajaran berlangsung, mengobrol dengan teman pada saat jam pelajaran berlangsung, dan tidak mengumpulkan tugas tepat waktu. Permasalahan tersebut apabila dibiarkan, maka akan menjadi permasalahan umum yang dilakukan oleh banyak siswa, sehingga proses belajar mengajar di sekolah jauh dari keberhasilan yang diharapkan. Oleh karena itu diperlukan penanganan dalam upaya membantu siswa agar dapat meningkatkan kedisiplinan di sekolah. Penanganan tersebut antara lain dapat dilakukan dengan pemberian layanan Konseling Kelompok dengan Menggunkan Teknik Behavior Contract.

Layanan konseling kelompok sangat dibutukan dalam pelaksanaan karakter disiplin layanan konseng kelompok adalah layanan bimbingan dan konseling yang diberikan kepada sekelompok individu. Sukardi (2002) mengungkapkan bahwa, "layanan konseling kelompok yaitu layanan bimbingan dan konseling yang memungkinkan peserta didik memperoleh kesempatan untuk pembahasan dan penuntasan permasalahan yang dialaminya melalui dinamika kelompok.

Ada beberapa alasan pentingnya dengan adanya layanan Konseling Kelompok dengan teknik Behavioral Contract khususnya dalam peningkatan karakter disipin siswa yaitu untuk mengajarkan 
siswa yang sangat beragam mulai dari sifat siswa, tingkat pemahaman sampai pada perilaku alami yang dialami pada masa perkembangannya seperti terlambat datang ke sekolah, mengulur-ulur waktu masuk kelas saat pergantianpelajaran, melanggar tata tertib sekolah, tidak mengerjakan tugas piket, dan mengabaikan tugas yang diberikan guru kepada siswa, berpakian tidak sopan. Keadaaan ini yang mendorong untuk diadakannya peningkatan karakter disiplin yang mendalam terutama siswa yang masih belum memahami karakter dirinya sendiri.

Berdasarkan Observasi dengan guru BK di SMA PGRI 2 Banjarmasin, pada tanggal 4 april 2017, masih terdapat siswa di sekolah tersebut yang kenyataannya kurang bisa menerapkan sikap dan perilaku disiplin di lingkungan sekolah tersebut. sekarang ini menggunakan penerapan sanksi bagi siswa yang melanggar peraturan sekolah yaitu dikenakannya sistem poin bagi siswa yang melanggar tata tertib sekolah. Jika poin yang dikenakan sudah memenuhi kapasitas sesuai dengan standar point yang ditentukan oleh peraturan sekolah maka pihak sekolah akan memberikan sanggi kepada siswa tersebut.

Bedasarkan Latar Belakang dan Urain ini tertulis untuk mengetahui lebih lanjut tentang bagaimanakah pengaruh Layanan Konseling Kelompok dengan Teknik Behavioral Contract dalam Menumbuhkan Karakter Disiplin Siswa di SMA PGRI 2 Banjarmasin Kelasa XI-IPS 2 pelajaran 2017-2018

\section{METODE}

Metode yang digunakan dalam penelitian ini adalah Penelitian Tindakan Bimbingan dan Konseling (PTBK). Menurut Tadjri (2014:9) Penelitian Tindakan Bimbingan dan Konseling (PTBK) merupakan penelitian kolaboratif yang dilakukan konselor berdasarkan refleksi diri dengan tujuan untuk memperbaiki mutu layanan BK agar kesejahteraan siswa meningkat. Adapun populasi dalam penelitian ini adalah siswa SMA PGRI 2 Banjarmasin kelas XIIPS 2 berjumlah 40 siswa. Adapun sempel dalam penelitian ini adalah siswa SMA PGRI 2 Banjarmasin yang berjumlah 7 orang diantanya 6 siswa laki-laki dan 1 siswa perempuan dengan inisial AHS XI-IPS 2, ANP XI-IPS 2, AT-IPS 2, MK-IPS 2, MS-IPS 2, MTIPS 2, RL-IPS 2 yang di identifikasi pernah tidak disiplin. Dalam teknik pengambilan sampel peneliti menggunakan teknik purpose sampling, menurut Sugiyono (2015:300) purposive sampling adalah teknik pengambilan sampel sumber data dengan pertimbangan tertentu. Pertimbangan tertentu ini, misalnya orang tersebut yang dianggap paling tau tentang apa yang kita harapkan, atau mungkin dia sebagai penguasa sehingga akan memudahkan peneiti
ISSN. 2460-9722

menjelajahi obyek/situasi social yang diteliti. Dalam proses penelitian ini peneliti merencanakan dengan 2 siklus, dan siklus tersebut adalah sebagai berikut. Pelaksanaan penelitian ini dilakukan dengan dua siklus. Dan proses penelitian tindakan kelas adalah prencanaan, pelaksanaan, pengamatan, dan refleksi.

Yang dapat di paparkan sebagai berikut:

\section{Rencana}

Menurut Tadjri (2014:51-57) langkahlangkah menyusun rencana tindakan meliputi : (1) Rumusan hipotesis, (2) Menentukan jumlah siklus tindakan, (3) Materi tindakan. Adapun perencanaan tindakan dalam penelitian yang akan peneliti laksanakan adalah: (1) Membuat rencana pelaksanaan layanan konseling kelompok dengan teknik behavioral contract yang meliputi waktu, tempat dan siswa yang dijadikan objek penelitian, (2) Menentukan jumlah siklus, yaitu dua siklus dengan satu siklus yang terdiri, (3) Menyiapkan RPL beserta materi/topic bahasan dalam pelaksanaan layanan konseling kelompok sesuai dengan aspek, (4) Menyiapkan sumber, bahan dan alat bantu yang diperlukan.

\section{Pelaksanaan}

Dalam pelaksaan Penelitian Tindakan yang akan peneliti lakukan adalah:

1) Tahap pembentukan kelompok;

(a) Peneliti menyampaikan maksud dan tujuan dari konseling kelompok

(b) Menjelaskan cara-cara dan asas-asas kegiatan konseling kelompok

(c) Saling mengungkapkan dan mengenalkan diri, (d) Menyiapkan perjanjian kontrak.

2) Tahap peralihan

(a) Menjelaskan kegiatan yang akan di tempuh pada tahap berikutnya

(b) Mengamati apakah para anggota kelompok apakah sudah siap menjalani kegiatan pada tahap berikutnya

(c) Membahas suasana yang terjad Meningkatkan kemampuan keikutsertaan anggota

3) Tahap kegiatan

(a) Masing-masing anggota bebas mengemukakan masalah

(b) Menetapkan masalah yang akan di bahas terlebih dahulu

(c) Anggota membahasa masalah secara mandalam

(d) Ikut serta dalam seluruh kegiatan kelompok

4) Tahap penutup

(a) Peneliti menyatakan bahwa kegiatan akan segera berakhir

(b) Pemimpin dan anggota kelompok mengemukakan kesan dan hasil kegiatan

(c) Membahas kegiatan lanjutan

(d) Mengemukakan pesan dan harapan

\section{Pengamatan}

\section{Dipublikasikan Oleh:}


Menurut Tadjri (2014:40) pengamatan adalah teknik pengumpulan data dengan cara peneliti mengamati secara visual objek yang diamati. Tujuannya adalah untuk memperoleh data factual dan riil suatu objeksebagaindasar untuk menyusun deskripsi, seleksi dan analisis. Menurut Hidayat dan Bandrujaman (2012:61-62) pengamatan dapat di kelompokan menjadi dua yaitu pengamatan terhadap proses dan hasil,pengamatan terhadap proses pada umumnya meliputi pengamatan terhadap ketepatan prosedur pelaksanaan tindakan yang dilakukan guru $\mathrm{BK} /$ peneliti, data mengenai keaktifan siswa, serta tentang tanggapan/kepuasan siswa dalam mengikuti layanan. Pengamatan dalam penelitian ini menggunakan skala penilaian. Menurut Anwar Sutoyo (2014:84) skala penilaian adalah pencatatn gejala menurut tingkattingkatannya. Bentuk pencatatn ini bukan hanya menggambarkan ada atu tidaknya gejala pada subjek yang sedang di amati seperti pada daftar ceklis, tetapi lebih dari itu berupaya menggambarkan kondisi subjek sesuai tingkatan-tingkatan gejalanya. Menurut Sutrisno Hadi (dalam Anwar Sutuyo, 2014:85) penggunaan rating scale ini sangat popular karena penggunaanya sangat mudah, di sisi lain pencatatannya lebih menunjukan keseragaman antara pencatat satu dengan lainnya, dan sangat sederhana untuk di analisis secara statistik.Adapun pedoman untuk pengamatan prosedur pelaksaan tindakan dan keaktifan siswa terlampir. Data hasil adalah data yang berkenaan dengan hasil/dampak dari tindakan yang di berikan. Pengamatan terhadap hasil dilakukan untuk melihat keberhasilan tinadakan variable masalah dalam PTBK. Data hasil itulah yan kemudian kita paparkan untuk menentukan apakah tindakan yang dilakukan berhasil atau tidak. Adapun pedoman pengamatan hasil terlampir. Di dalam pengamatan peneliti berkolaborasi dengan teman sejawat untuk mengamati pelaksanaan tindakan dan mengamati keaktifan siswa.

\section{Refleksi}

Menurut Tadjri (2014:45) data hasil pengamatan digunakan sebagai bahan refleksi diri dasar untuk melakukan PTBK. Refleksi yang mengandung arti memantulkan kembali/ mengungkapkan kembali merenungkan kembali menyatakan kembali. Hasil pengamatan yang terdokumentasi merupakan data pendukung yang sangat bermanfaat untuk refleksi diri. Pada tahap ini peneliti akan mengevaluasi proses pelaksanaan konseling kelompok dan mengevaluasi hasil frekuensi siswa membolos sebelum mengikuti konseling kelompok dengan teknik bevioral contract dan sesudah mengikuti konseling kelompok dengan teknikbehavioral contract .

Untuk mengetahui kebershasilan perbaikan di perlukan data yang dikumpulkan selama PTBK berlangsung. Dalam penelitian ini peneliti menggali data dengan menggunakan tiga cara yaitu observasi, wawancara, dan dokumentasi, yaitu:

\section{Observasi}

Menurut Anwar Sutuyo (2014:69-71) secara garis besar terdapat dua rumusan tentang pengertian observasi, yaitu pengertian secara sempit dan luas. Dalam arti sempit, observasi berarti pengamatan secara langsung terhadap gejala yang diteliti, dalam arti luas, observasi meliputi pengamatan yang dilakukan secara langsung maupun tidak langsung terhadap obyek yang sedang diteliti. Ada beberapa bentuk observasi yang lazim dilakukan oleh konselor dan atau peneliti, salah satunya yaitu observasi nonpartisipan. Observasi non-partisipan, yaitu bila observer tidak terlibat secara langsung atau tidak berpartisipasi dalam aktivitas yang sedang dilakukan observee. Dalam penelitian ini peneliti melakukan observasi non-partisipan, dan menggunakan beberapa alat bantu seperti skala penilaian untuk mengamati pelaksanaan tindakan, mengamati keaktifan siswa, dan mengamatihasil.

\section{Wawancara}

Menurut Tadjri (2014:65) Wawancara sebagai alat pengumpulan data adalah suatu cara pengumpulan data dengan mengadakan pembicaraan atau tanya jawab secara lisan antara orang yang mewawancarai dengan yang di wawancarai. Tujuan wawancara adalah untuk memperoleh data otentik dari sumber pertama yang berupa pernyataan wawancara dalam penelitian ini berbentuk wawancara tak berstruktur. Menurut Sugiyono (2015:320) wawancara tidak terstruktur adalah wawancara yang bebas dimana peneliti tidak menggunakan pedoman wawancara yang telah tersusun secara sistematis dan lengkap untuk pengumpulan datanya. Pedoman wawancarayang digunakan hanya berupa garis-garis besar permasalahan yang akan di tanyakan.Wawancara dilakukan kepada guru BK, guru mata pelajaran serta wali kelas XI-IPS 2 di SMA PGRI 2 Banjarmasin guna memperoleh data berupa frekuensi siswa tidak disiplin sebelum mengikuti konseling kelompok dengan tekniik behavioral contract dan frekuensi siswa setelah mengikuti konseling kelompok dengan teknikbehavioral contract.

\section{Dokumentasi}

Menurut sugiyono (2015:329) dokumen adalah catatan peristiwa yang sudah berlalu. Dokumen bisa berbentuk tulisan, gambar, atau karya-karya monumental dari seseorang. Dokumentasi dalam penelitian ini perilaku siswa membolos dilihat dari buku catatan harian yang di kelola oleh guru BK SMA PGRI 2 Banjarmasin. PTBK adalah penelitian yang lebih banyak menggunakan pendekatan kualitatif. Salah satu bentuk analisis dalam pendekatan kualitatif 
adalah analisis deskriftif. Dalam penelitian ini peneiti menggunakan analisis deskriftif kualitatif. Menurut Tadjri (2014:71-72) analisis deskriftif adalah analisis dengan menggambarkan data sebagaimana adanya, tidak menambah dan tidak pula megurangi.

\section{HASIL DAN PEMBAHASAN}

Untuk mengetahui kondisi awal siswa yang tidak disiplin di SMA PGRI 2 Banjarmasin penelitian melakukan Wawancara dilakukan dengan guru BK sekaligus menerapkan buku mata pelajaran dibidang Mulok (Muanta Lokal) di SMA PGRI 2 Banjarmasin nama ibu Bk itu sendiri alah Hayatun Purnama Sari, S.Pd

Table 1 Kondisi Awal Perilaku Siswa Membolos Sebelum Mengikuti Layanan Konseling Kelompok dengan Teknik Behaviora Contract Siklus 1 dan siklus 2

\begin{tabular}{|l|l|l|l|}
\hline NO & Nama Siswa & Kelas & Fekuensi \\
\hline 1 & AT & XI-IPS 2 & 4 \\
\hline 2 & AHS & XI-IPS 2 & 5 \\
\hline 3 & & XI-IPS 2 & 5 \\
\hline 4 & MK & XI-IPS 2 & 6 \\
\hline 5 & MS & XI-IPS 2 & 3 \\
\hline 6 & MT & XI-IPS 2 & 2 \\
\hline 7 & RL & XI-IPS 2 & 3 \\
\hline
\end{tabular}

Berdasarkan tabel di atas dapat di diketahui bahwa MK sebelum mengikuti layanan konseling kelompok dengan teknik behavioral contract sebanyak 6 kali, AHS sebanyak 5, ANP sebanyak 5, AT sebanyak 4, MS sebanyak 3, RL sebanyak 3, dan MT sebanyak 2

Gambaran saat pelaksanaan layanan konseling kelompok dengan teknik behavioral contract siklus 1 dan 2.

Siklus 1

Untuk pengamatan hasil setelah pelaksanaan siklus 1 dilihat dari catatan harian guru BK yang sekaligus merangkap sebagai guru mata pelajaran di SMA PGRI 2 Banjarmasin pada hari Jumat, 31 Juli 2017 adapun hasil observasi tersebut sebagai berikut :

Tabel 2 Hasil Pascatindakan Setelah Siswa Mengikuti Layanan Konseling Kelompok dengan Teknik Behavioral Contract Siklus 1

\begin{tabular}{|l|l|l|l|}
\hline No & Identias & Kelas & Frekuensi \\
\hline 1 & AP & XI-IPS2 & 1 \\
\hline 2 & AHS & XI-IPS2 & 1 \\
\hline 3 & ANP & XI-IPS2 & 2 \\
\hline 4 & MK & XI-IPS2 & 1 \\
\hline 5 & MS & XI-IPS2 & 2 \\
\hline 6 & MT & XI-IPS2 & 0 \\
\hline 7 & RL & XI-IPS2 & 0 \\
\hline
\end{tabular}

Berdasarkan table di atas dapat diketahui bahwa setelah mengikkuti layanan konseling kelompk
ISSN. 2460-9722

terdapat dua siswa yang mengikuti peraturan disiplin Sedengkan 5 orang lainnya mengalami pengurangan kelima siswa tersebut adalah AT sebanyak 2, AHS sebanyak 2, ANP sebanyak 3, MK sebanyak 3, MS sebanyak 1, untuk mengetahui pengukuran perilaku siswa tidak disiplin sebelum mengikuti layanan konseling kelompok dengan teknik behavioral contract dan setelah mengikuti layanan.

Tabel 3 Penguranagan Perilaku Siswa Tidak Disiplin Sebelum dan Setelah Siswa Mengikuti Layanan Konseling Kelompok dengan Teknik Behavioral Contract Siklus 1

\begin{tabular}{|l|l|l|l|l|l|}
\hline $\begin{array}{l}\text { N } \\
\text { O }\end{array}$ & $\begin{array}{l}\text { Identita } \\
\text { s }\end{array}$ & $\begin{array}{l}\text { Kela } \\
\text { s }\end{array}$ & $\begin{array}{l}\text { Kondis } \\
\text { i Awal }\end{array}$ & $\begin{array}{l}\text { Siklu } \\
\text { s 1 }\end{array}$ & $\begin{array}{l}\text { Pengukura } \\
\text { n }\end{array}$ \\
\hline 1 & AT & $\begin{array}{l}\text { XI- } \\
\text { IPS2 }\end{array}$ & 4 & 2 & 2 \\
\hline 2 & AHS & $\begin{array}{l}\text { XI- } \\
\text { IPS2 }\end{array}$ & 5 & 2 & 3 \\
\hline 3 & ANP & $\begin{array}{l}\text { XI- } \\
\text { IPS2 }\end{array}$ & 5 & 3 & 2 \\
\hline 4 & MK & $\begin{array}{l}\text { XI- } \\
\text { IPS2 }\end{array}$ & 6 & 3 & 3 \\
\hline 5 & MS & $\begin{array}{l}\text { XI- } \\
\text { IPS2 }\end{array}$ & 3 & 1 & 4 \\
\hline 6 & MT & $\begin{array}{l}\text { XI- } \\
\text { IPS2 }\end{array}$ & 2 & 1 & 1 \\
\hline 7 & RL & $\begin{array}{l}\text { XI- } \\
\text { IPS2 }\end{array}$ & 3 & 2 & 1 \\
\hline
\end{tabular}

Dilihat dari table diatas siswa mengikuti layanan konseling kelompok denga teknik behavioral contract pada siklus 1 adagan pengurangan perilaku displin mengurangan perilaku siswa disiplin masing-masing AT sebanyak 2 kali, AHS sebanyak 2 kali, ANP sebanyak 3, MK sebanyak 3 kali, MS sebanyak 1 kali. Siklus 2

Berdasarkan hasil observasi pengamatan hasil akhir atau postest siklus 2 yang dilaksanakan pada hari Rubu, 9 Agustus 2017 dilihat buku catatan harian guru

BK SMA PGRI 2 Banjarmasin diperoleh hasil sebagai berikut:

Table 4 Hasil Pascatindakan Setelah Siswa Mengikuti Layanan Konseling Kelompok dengan Teknik Behavioral Contract Siklus 1 dan Siklus 2

\begin{tabular}{|l|l|l|l|}
\hline No & Identias & Kelas & Frekuensi \\
\hline 1 & AP & XI-IPS2 & 1 \\
\hline 2 & AHS & XI-IPS2 & 1 \\
\hline 3 & ANP & XI-IPS2 & 2 \\
\hline 4 & MK & XI-IPS2 & 3 \\
\hline 5 & MS & XI-IPS2 & 1 \\
\hline 6 & MT & XI-IPS2 & 1 \\
\hline 7 & RL & XI-IPS2 & 1 \\
\hline
\end{tabular}

Dipublikasikan Oleh:

UPT Publikasi dan Pengelolaan Jurnal

Universitas Islam Kalimantan Muhammad Asyad Al-Banjarmasin 
Berdasarkan tabel di atas diperoleh peningkatan Disiplin siswa setelah melakukan layanan konselng kelompok pada siklus 2 Dari 7 anggota kelompok yang tergolong pada siklus 2 ini. Dengan masing masing memiliki tingkat disiplin belajar sebagai berikut: AT-IPS2, sebesar 2 dengan kriteria tinggi, ANP-IPS2, sebesar 2 dengan kriteria tinggi, AHS sebesar dengan kriteria tinggi, MK-IPS2, sebesar 1 dengan kriteria tinggi, MS-IPS2, 1sebesar dengan kriteria tinggi, MT-IPS2, 1 sebesar dengan kriteria tinggi,RL-IPS2, 0

Gambaran siswa setelah mengikuti layanan konseling kelompok dengan teknik behavioral contract siklus 1 dan siklus 2.

Setelah siswa mengikuti layanan konseling kelompok dengan teknik behavioral contract sebanyak tiga kali pertemuan di siklus 1 dua kali pertemuan dan di siklus 2 satu kali pertemuan terjadi pengurangan perilaku siswa tidak disiplin, untuk lebih jelas lihat table berikut :

Table 5 Hasil Pengurangan Perilaku Siswa tidak disiplin dari Kondisi Awal, Setelah Siklus 1 sampai Setelah Siklus 2 Mengikuti Layanan Konseling Kelompok dengan Teknikbehavioral contract.

\begin{tabular}{|c|c|c|c|c|c|}
\hline \multirow{2}{*}{$\begin{array}{l}\mathrm{N} \\
\mathrm{O}\end{array}$} & \multirow{2}{*}{$\begin{array}{l}\text { Nam } \\
\text { a }\end{array}$} & \multirow{2}{*}{$\begin{array}{l}\text { Kela } \\
\text { s }\end{array}$} & \multicolumn{3}{|c|}{ Siklus 2} \\
\hline & & & $\begin{array}{l}\text { Preste } \\
\mathrm{s}\end{array}$ & $\begin{array}{l}\text { Postes } \\
\mathrm{t}\end{array}$ & $\begin{array}{l}\text { Pengukura } \\
\mathrm{n}\end{array}$ \\
\hline 1 & AT & $\begin{array}{l}\text { XI- } \\
\text { IPS2 }\end{array}$ & 3 & 1 & 2 \\
\hline 2 & AHS & $\begin{array}{l}\text { XI- } \\
\text { IPS2 }\end{array}$ & 3 & 1 & 2 \\
\hline 3 & ANP & $\begin{array}{l}\text { XI- } \\
\text { IPS2 }\end{array}$ & 4 & 2 & 2 \\
\hline 4 & MK & $\begin{array}{l}\text { XI- } \\
\text { IPS2 } \\
\end{array}$ & 4 & 3 & 1 \\
\hline 5 & MS & $\begin{array}{l}\text { XI- } \\
\text { IPS2 } \\
\end{array}$ & 2 & 1 & 1 \\
\hline 6 & MT & $\begin{array}{l}\text { XI- } \\
\text { IPS2 }\end{array}$ & 2 & 1 & 1 \\
\hline 7 & $\mathrm{RL}$ & $\begin{array}{l}\text { XI- } \\
\text { IPS2 }\end{array}$ & 1 & 1 & 0 \\
\hline
\end{tabular}

Berdasarkan tabel di atas diperoleh peningkatan Disiplin siswa setelah melakukan layanan konselng kelompok pada siklus 2 Dari 7 anggota kelompok yang tergolong pada siklus 2 ini. Dengan masing masing memiliki tingkat disiplin belajar sebagai berikut: AT-IPS2, sebesar 2 dengan kriteria tinggi, ANP-IPS2, sebesar 2 dengan kriteria tinggi, AHS sebesar dengan kriteria tinggi, MK-IPS2, sebesar 1 dengan kriteria tinggi, MS-IPS2, 1sebesar dengan kriteria tinggi, MT-IPS2, 1 sebesar dengan kriteria tinggi,RL-IPS2, 0

Dipublikasikan Oleh:

\section{PEMBAHASAN}

Berdasarkan hasil penelitian Layanan konseling kelompok dengan teknik behavioral contract dalam meumbuhkan karakter disiplin siswa kelas XI-IPS2 di SMA PGR 2 Banjarmasin. Dapat dihasil bahwa disiplin dapat ditingkatkan melalui layanan konseling kelompok. Layanan konseling kelompok ini dilaksanakan sebanyak dua siklus. Siklus 2 digunakan sebagai penyempurna pada siklus 1.

Dalam Peneltian Tindak Bimbingan dan Konseling (PTBK) penelitan melakukan tindakan layanna konseling kelompok dengan menggunkan teknik behavioral contract bertujuan memberi pemahaman, pengembangan, dan dapat menyeluarkan kemampuannsecara maksimal serta dapat menghadapi tantangan secara realistis dimasa yang akan datang. Untuk itu harus memiliki haras disiplin terlebih dahulu untuk sebagai modal meraih kesuksesan.

Penelitian yang saya gunakan menggunkan teknik perjanjian kontrak yang dimana siswa yang tujuh orang itu bersedia untuk menjalankan kontaknya. Dari penelitian ini hampir sama dengan teori dari Fauzan (2009:21) mengatakan bahwa Behavior Contract adalah perjanjian dua orang ataupun lebih untuk berperilaku dengan cara tertentu dan untuk menerima hadiah bagi perilaku itu. Kontrak ini menegaskan harapan dan tanggung jawab yang harus dipenuhi dan konsekuensiny Bedasarkan kondisi awal secara keseluruhan sebelum di beri tindakan layanan konseling kelompk maka hasil yang diperoleh dari obervasi dan wawancara yaitu : Menumbuhkan karakter disiplin pada siswa dikelas XI-IPS2 di SMA PGRI 2 Banjarmasin sangat rendah dan belum dikatakan tinggi dikeenakan masih banyak siswa yang tidak disiplin dilingkungan sekolah.

Hal itu terjadi dikerenakna siswa belum mendapatkan tindakan layanan konseling kelompok dengan menggunkan teknik behavioral conract untuk menumbuhkan karakter disiplin siswa pada kelas XIIPS2 Banjarmasin. Maka dari hal tersebut penelitian sama guru BK merencanakan pemberian tindakan layanna konseling kelompok denga menggunkan teknik behavioral contract pada siswa. Pemberian layanan konseling kelompok bertujuan untuk memperbaiki proses layanan yang sudah dilakukan oleh guru BK yang belum maksimal dan untuk meningkatkan serta mengetahui gambaran disiplin pada siswa dalam mengemukan pendapat melalui layanan konseling kelompok menggunkana media pelaksanaan layanan, dilakukan dengan dua siklus yang terdiri dari mpat tahapan yaitu perencanaan (Planning) , Tindakan (Action), Pengamatan (Observasion), Refleksi (Reflection). Setelah diberikan layanan konseling kelompok pada siklus 1 sebanyak 2 kali pertemuan dengan metode ceramah 
dan diskusi dan materi layanan Disiplin di dalam kelas yaitu menumbuhkan sifat siswa agar diisplin dalam waktu tidak meninggalkan kelas, dan disiplin diluar kelas yaitu untuk menumbuhkan sifat tanggung jawab siswa terhadap peraturan disekolah selama dua hari berturut-turut dan diakhiri dengan melihat hasil siklus 1 ternyata disiplin siswa kelas XI-IPS2 mulai meningkkat, diketahui dari hasil analisis terjadi peningkatan pada disiplin siswa pada siklus 1 di kategori sedang. Tingkat disiplin masing-masing siswa di katogoring sedang yaitu AT-IPS2, sebesar 2 kriteria sedang AHS-IPS2, sebesar 3 kriteria sedang ANP-IPS2, sebesar 2 kriteria sedang MK-IPS2, sebesar 3 kriteria sedang MS-IPS2 sebesar 4 kriteria sedang, MT-IPS2, sebesar 2 kriteria sedang RL-IPS2, sebesar 1 kriteria sedang.

Dari deskripsi tindakan siklus II menunjukan bahwa proses pelaksanaan layanan konseling kelompok menggunakan teknik behavioral contract berjalan dengan lancar dan efektif. Berdasarkan hasil pelaksanaan layanan konseling kelompok pada siklus 1 dan siklus 2, tidak disiplin siswa menjadi meningkat. Hal ini dibuktikan hasil dari diskripsi prosentase disiplin menunjukkan peningkatan yang tinggi. Sebelum diberikan tindakan berupa layanan konseling kelompok rata-rata siswa tingkat displin siswa dalam tingkat rendah, namun setelah diberikan layanan konseling kelompok selama berapa kali pertemuan rata-rata tingkat tidak disiplin siswa menjadi tinggi. Selain dari hasil deskriptif postest tidak disiplin siswa, peningkatan siswa juga dapat terlihat dari hasil observasi yang dilaksanakan selama kegiatan layanan berlangsung di ruangan kelas dengan bantuan guru wali kelas XI-IPS2 sebagai kolaborator. Peningkatan siswa yang dapat terlihat antara lain adalah siswa menjadi lebih menaati peraturan, siswa lebih rajin dalam mengerjakan tugastugas, siswa lebih tepat waktu dalam mengumpulkan tugas, siswa tidak pernah lagi terlihat berkelahi, siswa terlihat lebih sopan dalam berpakaian, dan lain sebagainya. Hal tersebut menunjukkan bahwa tingkat displin siswa pada kelas XI-IPS2 di SMA PGRI2 Banjarmasin meningkat setelah mendapatkan layanan konseling kelompok. diketahui dari hasil analisis postest terjadi peningkatan pada disiplin siswa pada siklus 2 di kategori tinggi.

\section{PENUTUP}

Berdasarkan hasil penelitian yang telah dilakukan dan pembahasan hasil penelitian dengan judul mengurangi perilaku siswa membolos dengan teknik behavioral contract di SMA PGRI 2 Banjarmasin,dapat di simpulkan sebagai berikut :

1. Anggota kelompok terdiri atas 7 siswa yang tergolong dalam tidak disiplin siswa yang memiliki tingkat motivasi belajar tertinggi
ISSN. 2460-9722

dikelasnya berdasarkan perhitingan skala motivasi belajar. Penelitian menggunkan teknik behavioral contrcat, perjanjian kepada siswa yang tidak disiplin dikalukan disiklus1 dan siklus dua .Penelitian dilakukan dalam dua siklus, masing-masing siklus terdiri daridua pertemuan. Siklus 1 peneliti menggunakan metode ceramah dan diskusi, sedangkan siklus 2teteap mengunkan metode ceramah dan disikusi .

2. Ada beberapa hambatan yang ditemui selama pelaksaan siklus 1, diantaranya adalah anggota kelompok yang masih rebut, masih banyak, tetapi ada juga yang mendngarkan diruangka BK yang digunakan sebagai tempat dilaksanakannya kegiatan konseling kelompok walau agak kecil. Refleksi siklus 1 ini menjadi bahan pertimbangan dilaksanakannya siklus 2. pada siklus 2 kegiatan konseling kelompok dilakukan di ruang bk yang cenderung lebih kecil. Pada siklus 1 konseling kelompok dilaksanakan di ruang BK, pada siklus 2 tetap dilaksanakan di ruang bimbingan konseling. memberikan topik sesaui dengan meteri indikator pembahasan disetiap pertemuan, dan mengamati siswa selama kegiatan konsling kelompok berlangsung.

3. Dengan pelaksanaan konseling kelompok yang tepat untuk menumbuhkan karakter disiplin siswa. Hal ini dibuktikan dengan hasil analisis prostes pada kondisi awal disiplin siswa di katagori rendah, kemudian setelah diberikan layanan konseling kelompok pada siklus 1 meningkat menjadi katagori sedang, lalu meningkat lagi pada siklus 2 menjadi katagori tinggi.

\section{REFERENSI}

Adul, M, dan Dian Andayani. Pendidikan Karakter Perspaktif. Bandung: PT Remaja Rardakarya

Arsyad, Azhara. 2012. Strategi dan Implemnetasi Pendidikan karakter Bangsa. (online).Tersedia:http://azharaarsyad.uin-

Artiani, Hanif. Penenrapan Konseling Kelompok Behavioral Untuk Meningkatkan Disiplin Siswa. Surabaya: Hanif Artini

Auliah, Nurul.2005. Pengantar Pendidikan, Banjarmasin : Fkip Unsika

Eriorld.T.Bradley. 2015. 40 Tekinik . Yogjakarta: Pustaka Pelajar. 
Gunawan, H. 2012. Pendidikan Karakter. Bandung: Alfabta

Halimah, Nour. 20015. Upaya Sekolah Dalam Meningkatkan Disiplin Siswa. Banjarmasin: Unsika Banjarmasin.

Jarkawi. 2016. Penyeluruhan Tentang Cara Meningkatkan Percaya Diri Siswa dengan Fun Game Musyawarah Dengan Bimbingan dan Konseling. Banjarmasin: Universitas Islam Kalimantan MAB

Kamila, Z, M, 2013. Penanaman Karakter Disiplin dan Tanggung Jawab siswa. Yogjakata: Universitas Islam Nergi Sunan Kalijaga.

Khoirun ni'am, M. 2015. Penanaman Karakter Disiplin dan Tanggung Jawab Peserta Didik. Yogjakarta: Universitas Islam $\mathrm{N}$ sunan Kalijaga

Komalasari, G, W, Wahyuni. E, dan Kasih. 2011. Teori Dan Teknik Konseling. Jakarta Barat: Aditama

Koswara, E. 2009 Teori Dan Praktek Konselin dan Psikologi. Bandung: PT Unnes Press.

Kurnato,M.E. 2014 Konseling Kelompok. Bandung: Alfabeta

Latipun, 2008. Psikolog Konseling. Malang: UMM Pers

Lexy J.Moleong. 2001.Metodologi Penelitian Kualitatif, Bandung: Remaja Rosda Karya
ISSN. 2460-9722

Prayitno. 2001 Pengawasan Bimbingan dan Konseling di sekoloh dan Konseling di sekolah. Jakarta: Rineka

Sari, W, Eka 2015 Pembentukan Karkter Disiplin dar Tanggung Jawab. Yogjakara: Eka W sari

Sugiono.2015. Metode Penelitian pendidikan pendekatan luantitatif, kualitatif, dam $R \& D$. Bandung: Alfabeta

Sukardi, D, K. 2006 Pengantar Pelaksanaan Program Bimbingan dan Konseling. Jakarta: Rinck Cupta

Suryabrata, S. 2006. Psikologi Pendidikan. Jakarta: PT. Raja Grafindo Persada

Susanto,Didi.2014.Pembelajaran Dalam Mata Kuliah Pendidikan Kewarganegaraan. Banjarmasin:FKIP Uniska Banjarmasin

Tololiu, D. 2005. Meningkatkan Disiplin Siswa Melalui Bimbingan Induvidual Skripsi. Gorontalo: Universitas Nergi Gorontalo

Tulus, T. 2004 Peran dan Disiplin pada Perilaku dan Prestasi Siswa. Jakarta: Grasindo

Umar, R, Arni, 2012. Meningkatkan Kemandirin Anak Melalui Teknik Behavioral Contract, Gorontalo: Arni R.Umar

Winkel, S, W. dan M.M.Sri,H. 1991. Bimbingan dan Konseling Di Institusi Pendidikan, Yogjakarta: Media Abadi. 